\title{
NONDESTRUCTIVE EVALUATION OF SINTERED CERAMICS
}

\author{
George Y. Baaklini, Stanley J. Klima, \\ and William A. Sanders* \\ Structural Integrity Branch \\ NASA Lewis Research Center
}

\begin{abstract}
Radiography and several acoustic and thermoacoustic microscopy techniques are investigated for application to structural ceramics for advanced heat engines. A comparison is made of the results obtained from the use of scanning acoustic microscopy (SAM), scanning laser acoustic microscopy (SLAM), and thermoacoustic microscopy (TAM). These techniques are evaluated on research samples of green and sintered monolithic silicon nitrides and silicon carbides in the form of modulus-of-rupture (MOR) bars containing deliberately introduced flaws. Strengths and limitations of the techniques are described, with the emphasis being on statistics of detectability of flaws that constitute potential fracture origins. Further, it is shown that radiographic evaluation and guidance helped develop uniform high-density $\mathrm{Si}_{3} \mathrm{~N}_{4}$ MOR bars with improved four-point flexural strength $\left(875,544\right.$, and $462 \mathrm{MPa}$ at room temperature, $1200{ }^{\circ} \mathrm{C}$, and $1370{ }^{\circ} \mathrm{C}$, respectively) and reduced scatter in bend strength.
\end{abstract}




\section{OVERVIEW}

\section{ACOUSTIC MICROSCOPY}

SAM uses a single transducer to generate and receive ultrasonic energy (Nikoonahad, 1984). Good resolution and sensitivity are achieved by focusing moderately high-frequency ultrasonic energy ( 30 to $100 \mathrm{MHz}$ ) on a small spot, raster-scanning the lens with respect to the sample, and then time-gate sampling the reflected ultrasonic pulse amplitude. Any features that produce an acoustic impedance mismatch within the sample, or that produce a change in acoustic impedance at the specimen surface, can cause detectable variations in the digitized and stored spatial map of reflected signal amplitude. Images of microflaws are generally sharp. Depth location of flaws is easy to determine. Access is needed to only one side of the test sample. Further, SAM can be adapted to handle curved surfaces. Detection and resolution of microflaws are affected by (1) surface roughness (2) ultrasound depth of penetration, and (3) the aperture size of the lens. SAM images are not generally displayed in real time because computer time is needed to process the entire block of data used to produce the image.

\section{SAM IMAGE OF VOIDS IN A SILICON NITRIDE MOR BAR}

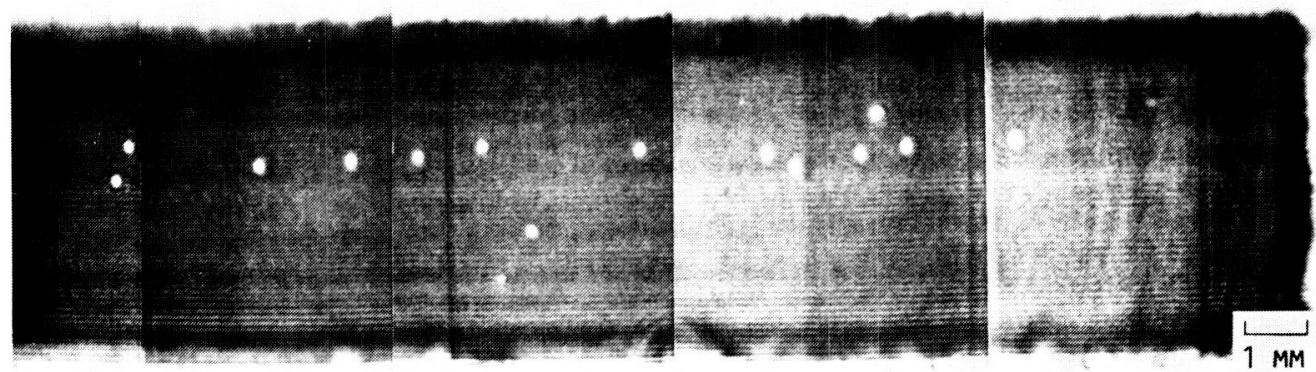

- SEEDED VOIDS (WHITE SPOTS) $20 \mu \mathrm{m}$ DIAMETER, $1 \mathrm{~mm}$ DEEP

- DIAMOND GROUND SURFACE, $2 \mu \mathrm{m}$ FINISH

- ULTRASONIC REFLECTION MODE

- 50 MHz TRANSDUCER, SPHERICALLY FOCUSED 


\section{DETECTION OF VOIDS WITH ACOUSTIC MICROSCOPY}

Scanning laser acoustic microscopy (SLAM) uses $100 \mathrm{MHz}$ ultrasonic waves that are transmitted through the specimen and are modulated by material surface and internal characteristics. The relative intensity and phase of the waves are detected by a laser beam that is raster-scanned over an area approximately $2 \mathrm{~mm}^{2}$. Features such as cracks, voids, density variations, etc. are displayed in real time on a video monitor at $\times 100$. SLAM images are affected by the surface roughness of the test object. Un1ike SAM, SLAM has a limited capability for handling complex shaped objects, and also requires access to opposite sides of the sample. The plot below summarizes SLAM probability of detection (POD) data obtained for internal voids in specimens with diamond-ground surfaces (Roth and Baaklini, 1986). The boundaries of the bar graphs indicate the minimum void sizes and maximum depths (from the laser-scanned surface) at which the $0.90 / 0.95 \mathrm{POD} /$ confidence level was achieved. Also shown is a single data point representing preliminary results obtained with the SAM technique. All of the 38 voids (nominal diameter $20 \mu \mathrm{m}$ ) were detected $1 \mathrm{~mm}$ below the surface of silicon nitride samples, yielding a POD better than $0.90 / 0.95$ (K1ima et al., 1986).

\section{0\% PROBABILITY OF DETECTION AT 95\% CONFIDENCE LIMIT}

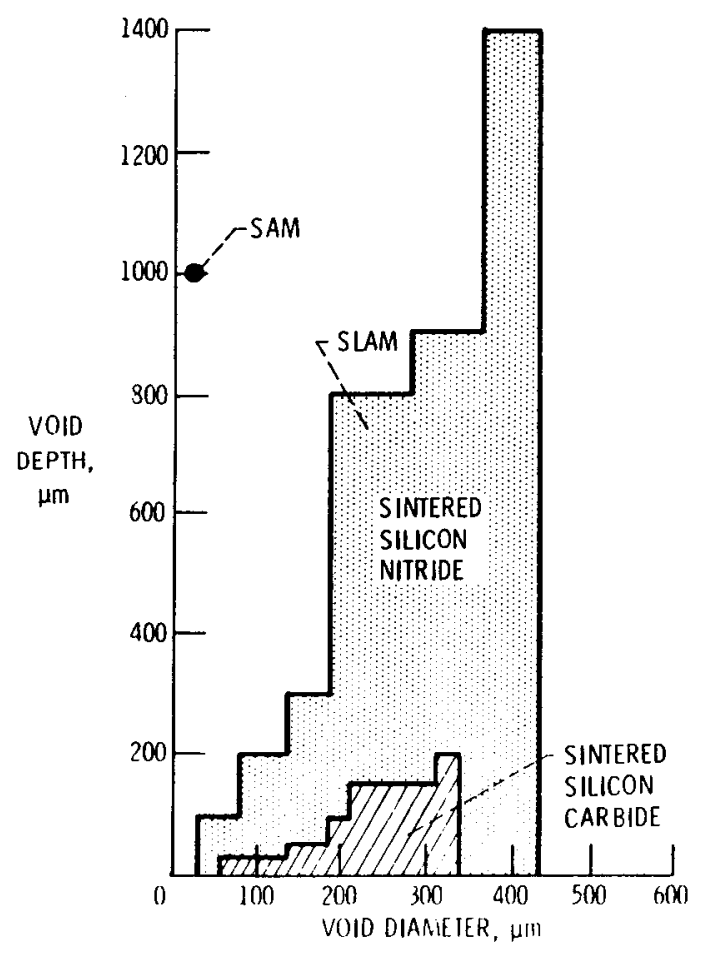




\section{POSTER PRESENTATION}

\section{THERMOACOUSTIC MICROSCOPY}

Thermoacoustic microscopy (TAM) measures relative differences in surface and near-surface thermal properties of the material being evaluated (Rosencwaig, 1980). The absorption of intensity-modulated electromagnetic radiation (usually a laser or an electron beam), focused at any point on the sample, gives rise to localized cyclic heating and cooling that, in turn, generates elastic waves at the modulation frequency. The amplitude and phase of these waves can be measured either at another location on the specimen surface by a piezoelectric crystal in contact with the specimen, or in the surrounding gas medium by a noncontacting method using a sensitive microphone. A sensitive, high-resolution image representing varying thermal characteristics of the sample can be generated point-by-point using this technique. Its applicability to engine parts can be limited by vacuum requirements, coating requirements, and shape complexity. By utilizing the electron beam method, TAM proved to be useful for detecting tight surface cracks and pits on research samples, as shown below (K1ima et a1., 1986).
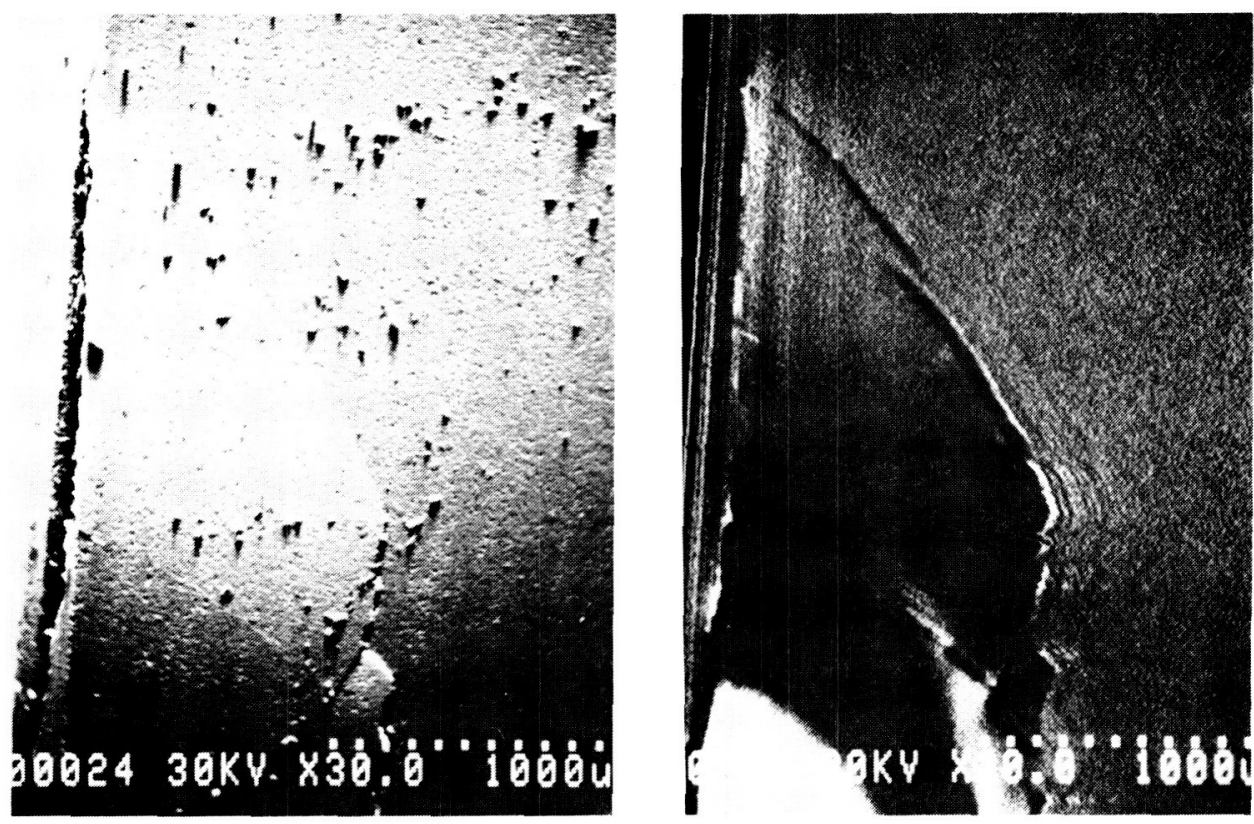

CD-88-32331 


\section{DETECTABILITY OF FRACTURE-CAUSING TYPE OF FLAWS VIA RADIOGRAPHY AND ACOUSTIC MICROSCOPY}

A comparison is made between acoustic and radiographic techniques for detecting fracture-causing defects such as voids, cracks, and inclusions. In general, acoustic microscopy is not applicable to green ceramics because either (1) the sample is damaged by the presence of a liquid-coupling medium or (2) the surface of the sample is damaged by the intensity of the laser or electron beam energy sources. However, acoustic microscopy can be successfully used to characterize small areas of sintered ceramic parts. Radiographic techniques are suitable for characterizing both green and sintered ceramics.

\begin{tabular}{|c|c|c|c|c|}
\hline TECHMLQUE & DEFECT TYPE & RESOLUTION & LIMITATIONS & COMPOMENT APPLICABILITY \\
\hline \multirow[t]{3}{*}{ SLAM } & CRACKS & UNDEFINED & \multirow{3}{*}{$\begin{array}{l}\text { SUAFACE ROUGHNESS, } \\
\text { MATERIAL DEPENDENT, } \\
\text { MEAR SURFACE }\end{array}$} & \multirow{3}{*}{$\begin{array}{l}\text { THIM SECTION, } \\
\text { SIMPLE SHAPES }\end{array}$} \\
\hline & voids & $25 \mu \mathrm{m}$ & & \\
\hline & INCLUSIONS & $25 \mu \mathrm{m}$ & & \\
\hline \multirow[t]{3}{*}{ sam } & CHACKS & UNDEFINED & \multirow[t]{3}{*}{ SURFACE ROUGHNESS } & \multirow[t]{3}{*}{ SMALL AREAS } \\
\hline & volos & $20 \mu \mathrm{m}$ & & \\
\hline & INCLUSIONS & $20 \mu \mathrm{m}$ & & \\
\hline \multirow{2}{*}{ TAM } & volos & $25 \mu \mathrm{m}$ & \multirow{2}{*}{$\begin{array}{l}\text { SUAFACAE CHEMISTRY, } \\
\text { ABSORPTIVITY, } \\
\text { NEAR SURFACE }\end{array}$} & \multirow[t]{2}{*}{ SMALL AREAS } \\
\hline & IMCLUSIONS & $25 \mu \mathrm{m}$ & & \\
\hline \multirow{3}{*}{$\begin{array}{l}\text { TAM } \\
\text { (ELECTRON } \\
\text { BEAM) }\end{array}$} & CRACKS & $1 \mu \mathrm{m}$ WIDE & \multirow{3}{*}{$\begin{array}{l}\text { SURFACE ROUGHNESS. } \\
\text { REQUIRES VACUUM, } \\
\text { REQUIRES COATIMG, } \\
\text { HEAR SURFACE }\end{array}$} & \multirow{3}{*}{$\begin{array}{l}\text { SIMPLE SHAPES, } \\
\text { SMALL AREAS }\end{array}$} \\
\hline & volos & $10 \mu \mathrm{m}$ & & \\
\hline & INCLUSIONS & $10 \mu \mathrm{m}$ & & \\
\hline \multirow{4}{*}{$\begin{array}{l}\text { MICROFOCUS } \\
X \text { RAY }\end{array}$} & CAACKS & ORIENTATION DEPENDENT & \multirow{4}{*}{$\begin{array}{l}\text { SMALL ABSORPIVITY } \\
\text { DIfFEAENCES }\end{array}$} & \multirow{4}{*}{$\begin{array}{l}\text { FILM-UNIFORM } \\
\text { THICKNESSES } \\
\text { REAL TIME-COMPLEX } \\
\text { GEOMETRIES, REDUCED } \\
\text { SEMSITIVITY }\end{array}$} \\
\hline & votos & $1-2 \%$ & & \\
\hline & INCLUSIONS & $.5 \%$ & & \\
\hline & GRADIENTS & $2 \%$ & & \\
\hline \multirow{4}{*}{$\begin{array}{l}\text { CT } \\
X \text { RAY }\end{array}$} & CAACKS & ORIENTATION DEPENDENT & \multirow[t]{4}{*}{ sLow } & \multirow[t]{4}{*}{ COMPLEX GEOMEJRIES } \\
\hline & votos & $<<1 \%$ & & \\
\hline & INCLUSIONS & $<<.5 \%$ & & \\
\hline & GRADIENTS & $<<2 \%$ & & \\
\hline
\end{tabular}




\section{RADIOGRAPHIC EVALUATION OF NASA $6 \mathrm{Y} \mathrm{Si}_{3} \mathrm{~N}_{4}$}

In mechanical properties of $\mathrm{Si}_{3} \mathrm{~N}_{4}$, scatter is generally attributed to defects and inhomogeneities occurring during powder processing and/or during fabrication of parts (Bowen, 1980, and Evans, 1982). Based on preliminary $\mathrm{x}$-radiographic characterization work on $\mathrm{Si}_{3} \mathrm{~N}_{4}$ by $\mathrm{Klima}$ (1986), a program was undertaken to systematically investigate density-gradient, flexural-strength relationships as affected by sintering and powder-processing variables for sintered $\mathrm{Si}_{3} \mathrm{~N}_{4}$. All batches were radiographically evaluated at all stages of $\mathrm{fab}-$ rication. Test bars were radiographed in the $(W, L)$ and $(T, L)$ modes where $x$ rays are transmitted through the thickness and the width of the bar, respectively.
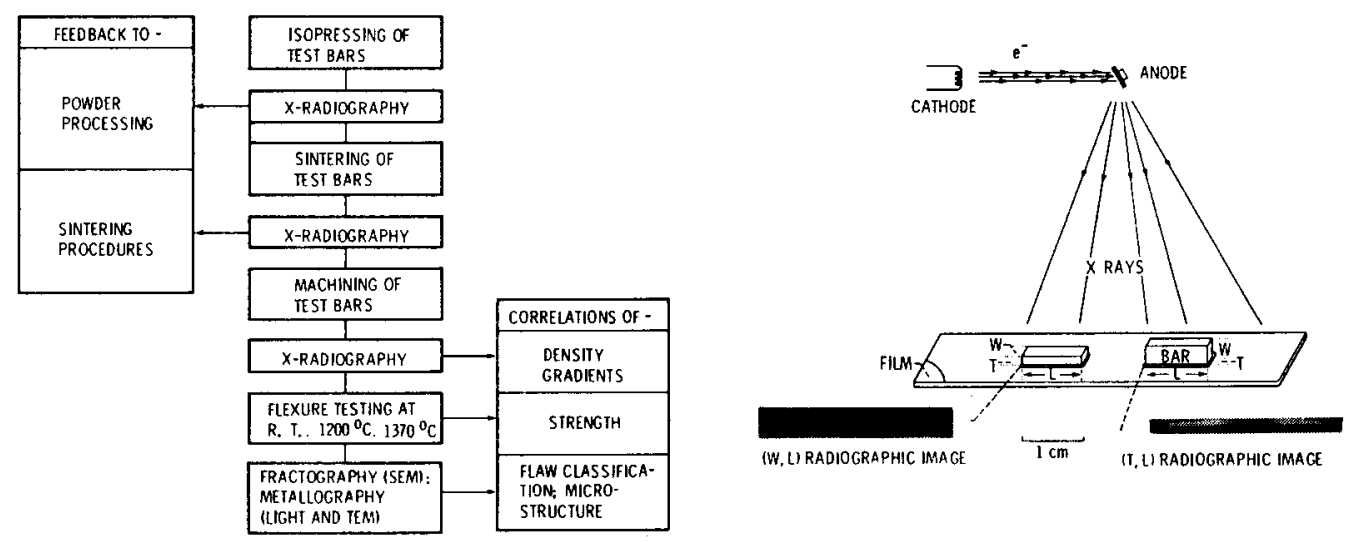


\section{COMBINED EFFECT OF MODIFIED PROCESSING/SINTERING PROCEDURES ON THE FLEXURAL STRENGTH OF NASA $6 \mathrm{Y} \mathrm{Si}_{3} \mathrm{~N}_{4}$}

The sintering variables were (1) temperature (2) nitrogen pressure $\left(P_{N}\right)(3)$ time $\left(t_{s}\right)$ (4) spacer contact area (BN), and (5) furnace position. The powderprocessing variables were (1) grinding time $t_{g}$ and (2) inclusion or exclusion of powder wet-sieving procedures. The cumulative positive effects of all the variables on flexural strength are shown below. (For more information, see Sanders and Baaklini (1988).) In processing from batch to batch (baseline to 28 to 29 to 31 ), the room-temperature strength continually increased, with an overall improvement of 56 percent, and more than a threefold reduction in the standard deviation. The summary of individual parameter effects on roomtemperature strength is shown in the table below. Strength improved 28 and 21 percent for 1200 and $1370^{\circ} \mathrm{C}$, respectively. All successive improvements in the mechanical properties were guided by $x$-radiographic characterization.

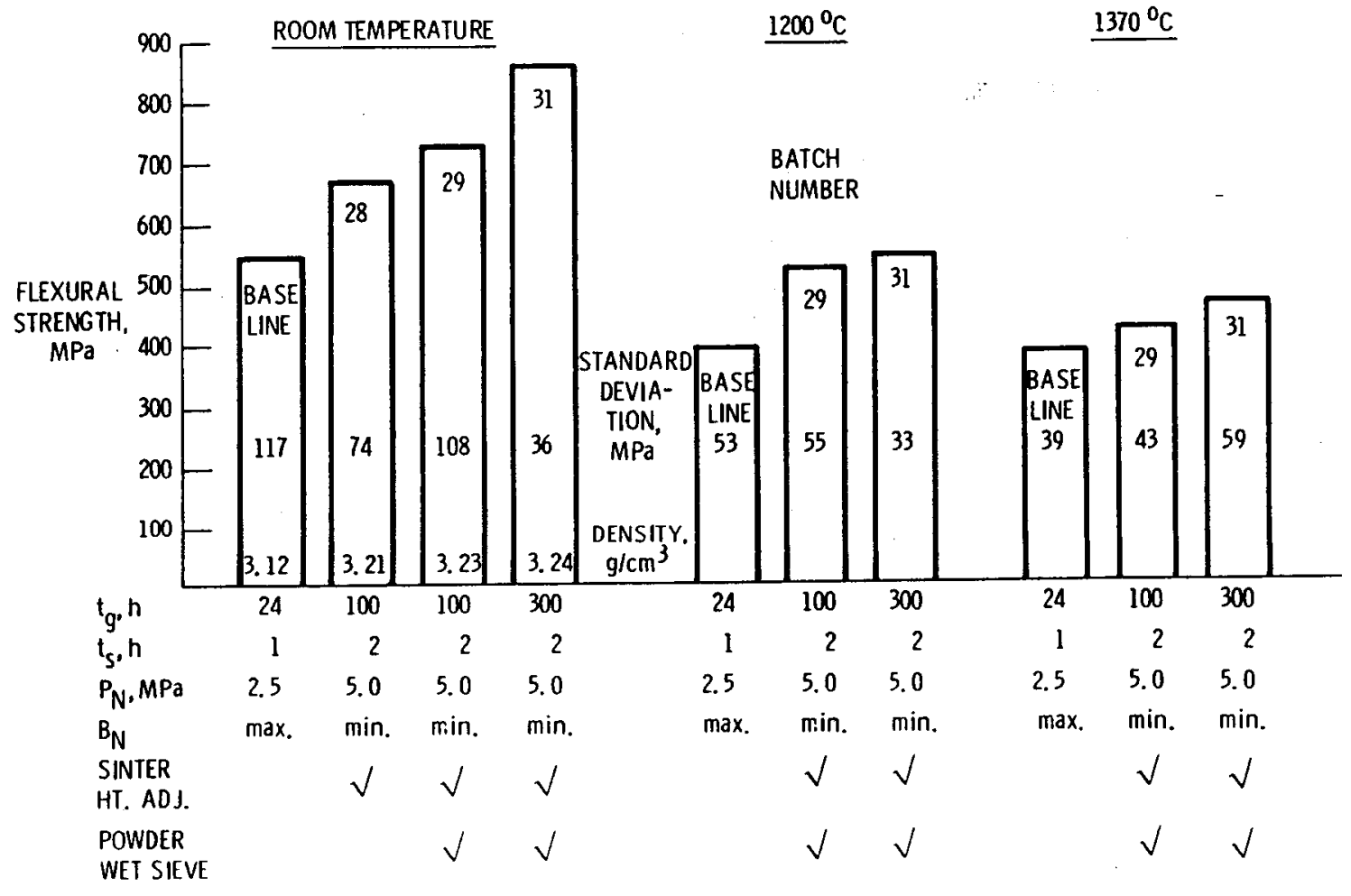




\section{INDIVIDUAL PARAMETER EFFECTS ON ROOM-TEMPERATURE STRENGTH}

\begin{tabular}{|c|c|c|c|}
\hline VARIABLE & LEVELS & $\begin{array}{c}\text { ROOM-TEMPERATURE } \\
\text { STRENGTH CHANGES, } \\
\text { MPA }\end{array}$ & CONCLUSIONS \\
\hline BN SPACER CONTACT & MAX $\rightarrow$ MIN & $+197 .+157$ & EXTREMELY HELPFUL \\
\hline SINTERING TIME & $\begin{array}{c}1 \rightarrow 1.25 \mathrm{HR} \\
1 \rightarrow 1.5 \mathrm{HR} \\
1 \rightarrow 2 \mathrm{HR}\end{array}$ & $\begin{array}{r}+129 \\
+87 \\
+145\end{array}$ & VERY HELPFUL \\
\hline SINTERING TEMPERATURE & $2050 \rightarrow 2140{ }^{\circ} \mathrm{C}$ & -117 & VERY HELPFUL \\
\hline SIEVING & NO $\rightarrow$ YES & +60 & HELPFUL \\
\hline GRINDING TIME & $\begin{aligned} 24 & \rightarrow 100 \mathrm{HR} \\
24 & \rightarrow 300 \mathrm{HR} \\
100 & -300 \mathrm{HR}\end{aligned}$ & $\begin{array}{c}-61,-13 \\
+41,+54 \\
+102,+67,+62,+125\end{array}$ & VERY HELPFUL \\
\hline SINTERING HEIGHT & $\mathrm{LOW} \rightarrow \mathrm{HIGH}$ & +24 & SLIGHTLY HELPFUL \\
\hline NITROGEN PRESSURE & $\begin{array}{l}2.5 \rightarrow 3.5 \mathrm{MPA} \\
3.5 \rightarrow 5.0 \mathrm{MPA} \\
2.5 \rightarrow 5.0 \mathrm{MPA}\end{array}$ & $\begin{array}{c}-205 \\
+45,+29,+24 \\
-181\end{array}$ & INCONCIUUSIVE \\
\hline
\end{tabular}

CD. $88-32334$ 


\section{NASA 6Y SINTERED SILICON NITRIDE IMPROVED BY RADIOGRAPHICALLY-GUIDED PROCESSING CHANGES}

\section{OETAR *ATT TS DE}

The successful use of conventional $x$-radiography in guiding the fabrication process resulted in denser and more uniform $\mathrm{Si}_{3} \mathrm{~N}_{4}$ over the baseline materials. Previously dominant failure-causing voids were replaced by large grains, which are less detrimental to strength properties. The improved structure can be attributed to (1) increased powder fineness that improves sinterability and uniformity (2) powder wet sieving that results in reduction of agglomerates and certain impurity particles (3) minimizing BN spacer contact that results in more uniform densification as a consequence of more uniform heating (4) an increase in sintering time from 1 to $2 \mathrm{hr}$, thus improving density and uniformity, and (5) raising sinter cup height to reduce the top bar to bottom bar temperature gradient.

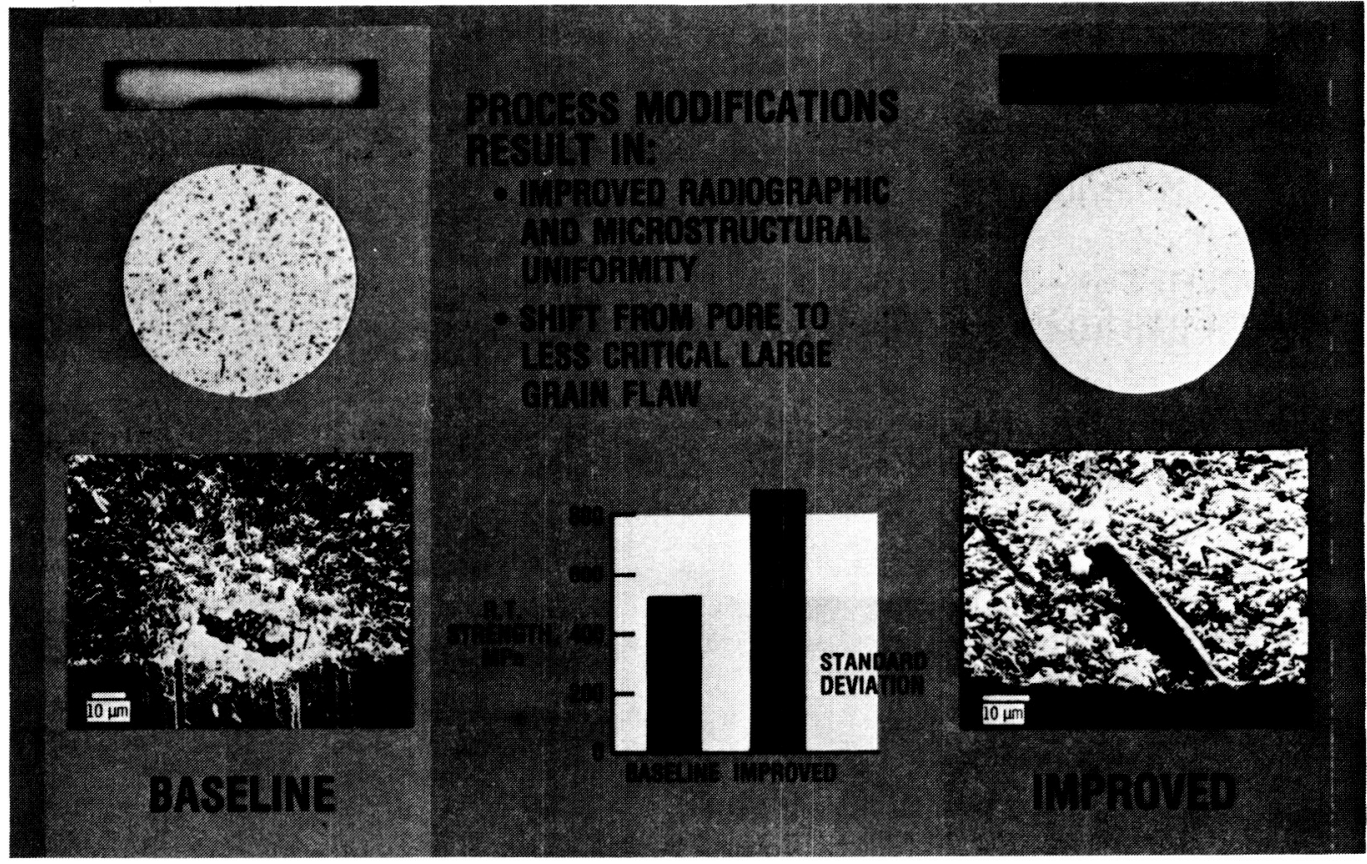

CD-88-32336 
- ACOUSTIC MICROSCOPY CAN BE USED TO CHARACTERIZE SMALL AREAS OF SINTERED CERAMIC PARTS, BUT IT IS NOT APPLICABLE TO GREEN PARTS

- RADIOGRAPHY IS SUITABLE FOR CHARACTERIZING BOTH GREEN AND SINTERED CERAMIC PARTS

- RADIOGRAPHY IS VERY BENEFICIAL IN GUIDING POWDER PROCESSING AND SINTERING PARAMETER CHANGES FOR IMPROVED $\mathrm{Si}_{3} \mathrm{~N}_{4}$

-IMPROVED $\mathrm{Si}_{3} \mathrm{~N}_{4}$ EXHIBITED HIGHER DENSITY, LOWER DENSITY GRADIENT, AND BETTER BAR-TO-BAR UNIFORMITY

-IMPROVED $\mathrm{Si}_{3} \mathrm{~N}_{4}$ POSSESSES LESS SCATTER IN BEND STRENGTH, IMPROVED STRENGTH, AND LESS CRITICAL DOMINANT FLAW 


\section{REFERENCES}

Bowen, H.K., 1980, "Basic Research Needs on High Temperature Ceramics for Energy Applications," Mater. Sci. Eng., Vol. 44, pp. 1-56.

Evans, A.G., 1982, "Consideration of Inhomogeneity Effects in Sintering," J. Am. Ceram. Soc., Vo1. 65, No. 10, pp. 497-501.

Klima, S.J., 1986, "NDE of Advanced Ceramics," Mater. Eval., Vo1. 44, No. 5, pp. 571-576.

Klima, S.J., Baaklini, G.Y., and Abe1, P.B., 1986, "Nondestructive Evaluation of Structural Ceramics," NASA TM-88978, presented at the 24th Automotive Technology Development Contractors' Coordination Meeting, Dearborn, MI, Oct. $27-30$.

Nikoonahad, M., 1984, "Reflection Acoustic Microscopy for Industrial NDE," in Research Techniques in Nondestructive Testing, R.S. Sharpe (ed.), Academic Press, London, Vol. 7, pp. 217-257.

Rosencwaig, A., 1980, Photoacoustics and Photoacoustic Spectroscopy, John Wiley and Sons, New York.

Roth, D.J., and Baaklini, G.Y., 1986, "Reliability of Scanning Laser Acoustic Microscopy for Detecting Internal Voids in Structural Ceramics," Adv. Ceram. Mater., Vo1. 1, No. 3, pp. 252-258.

Sanders, W.A., and Baaklini, G.Y., 1988, "Correlation of Processing and Sintering Variables with the Strength and Radiography of Silicon Nitride," Adv. Ceram. Mater., Vo1. 3, No. 1, pp. 88-94. 